\title{
$\underline{\operatorname{articles}}$
}

\section{The Value of Social Media Advertising Strategies on Tourist Behavior: A Game-Changer for Small Rural Businesses}

\author{
Nory B. Jones ${ }^{1}$, Patti Miles $^{1}{ }^{\mathrm{b}}$, Tanya Beaulieu ${ }^{1} \mathrm{c}$ \\ 1 University of Maine Business School \\ Keywords: rural business, social media, COBRA Model, advertising, tourist behavior, OLS regression. \\ https://doi.org/10.53703/001c.29478
}

\section{Journal of Small Business Strategy}

Vol. 31, Issue 4, 2021

\begin{abstract}
Nature-based tourism represents a growing sector within the tourism industry, and these interests could help improve the conditions of economically disadvantaged rural communities. The new digital landscape, including Internet and social media usage, represents a critical strategic opportunity to inform, educate and reach these tourism segments. The present research examines the impact of social media advertising on nature-based tourism within rural communities. In this research, we utilize the COBRA (Consumers' Online Brand-Related Activities) model (Muntinga et al., 2011) of consumer behavior to assess the impact social media advertising plays in generating Pre-Consumption, Consumption, Creation, Contribution, and Engagement in rural business. The results are significant, finding that incorporating digital strategies within rural firms is beneficial. According to our research, the careful placement of a social media advertisement can statistically increase engagement components by more than $50 \%$. In theory, this can increase tourism and economic activity in these rural, economically disadvantaged areas.
\end{abstract}

\section{Introduction}

Rural areas have unique challenges that make economic survival difficult. Geographically, $97 \%$ of the U.S. land area is classified as rural, and 60 million people (19.7\% of the U.S. population) live in these rural areas (U.S. Census Bureau, 2016). This research project takes place in one such area - rural Maine and investigates the challenges of many remote rural businesses. Given that small businesses account for $97-99 \%$ of all businesses in the United States ( $S B A$ Office of Advocacy, 2019), such an inquiry is certainly warranted. In Maine, for example, during 2019, small businesses contributed more than $\$ 12.9$ Billion to the Maine economy and created two out of three jobs (Maine Office of Tourism, 2019). Major challenges include sub-optimal access to broadband Internet, accessing needed capital, finding and retaining qualified workers, geographic isolation, and less expertise and knowledge of digital systems, including web and social media (Lane Report, 2019; NCSL, 2020). These obstacles may prevent small businesses in rural areas from reaching and attracting tourists.

Tourism can play a significant role in rural economies nationwide. For example, the Maine Office of Tourism reported that tourists spent about $\$ 4.8$ billion, which supported approximately 90,600 jobs and created an almost $\$ 9$ billion economic impact in Maine. Furthermore, they said that household income generated through jobs supported by tourism was more than $\$ 2.8$ billion (Maine Office of Tourism, 2019). Another example is demonstrated in South Dakota, where despite the pandemic in 2020, there were 12.6 million visitors, with 3.4 Billion in tourist spending, which generated $\$ 276$ million in state \& local tax revenue accounting for $11 \%$ of state sales tax collections (Dakota News, 2021). Similarly, tourism in Idaho is a $\$ 3.7$ billion business and employs more than 45,000 people, making it one of Idaho's largest industries (Robertson, 2021). In Maine, rural businesses provide approximately 116,000 jobs, equating to one in six jobs, contributing $\$ 2.8$ Billion to the state budget through tax dollars.

Nationally, tourism contributes a significant amount to

\footnotetext{
a Murphy Chair and Professor of Business Information Systems, University of Maine Business School, 5723 Donald P Corbett Business Building, Orono, ME 04469, njones@maine.edu Dr. Jones' research focuses on information systems strategy, rural small business and knowledge management.

b Associate professor at the Maine Business School, University of Maine Business School, 5723 Donald P Corbett Business Building Orono, ME 04469, patti.miles@maine.edu Her main research interest is statistical analysis, corporate social responsibility, and most recently Grit, Resilience, and Hardiness of Navy SEALs.

c Assistant professor of Business Information Systems, University of Maine Business School, 5723 Donald P Corbett Business Building, Orono, ME 04469, tanya.beaulieu@maine.edu Dr. Beaulieu's research focuses on crowdfunding and entrepreneur's use of technology.
} 
the economy. According to IBIS World (Kennedy, 2021), notwithstanding the pandemic in 2020, tourism provided $\$ 590.7$ Billion in revenue and employed about 5 million people across the United States. Nature-based tourism is defined as leisure travel to enjoy natural environments and outdoor activities and is especially pertinent to rural tourism. We can use the national parks as an indicator for rural nature-based tourism. The U.S. Department of the Interior (2020) reported that in 2019, visitor spending in communities near national parks resulted in a $\$ 41.7$ billion benefit to the nation's economy and supported 340,500 jobs annually. Global expenditures on tourism have increased from $\$ 456$ Billion to $\$ 1.4$ Trillion (U.S. Department of the Interior, 2020).

Digital transformation, especially in Web 2.0 and social media, has become a key player in a firm's success. However, many small and especially rural businesses have not taken advantage of these new forms of technologies. Given the scarcity of resources available to rural businesses, and the lack of time to learn new technologies, rural businesses do not always risk their precious resources to engage with newer technologies or to take advantage of features, such as social media advertising.

This research explores the use of social media advertising to analyze the impact on rural and nature-based tourism in economically depressed areas. The paper is organized as follows: A review of the literature provides a foundation for our research. We then propose four hypotheses based on the literature review. The methods section analyzes the impact of advertisements placed on Facebook for rural businesses. The results from this study are potentially generalizable to rural small businesses on a national and international scale.

\section{Literature Review Impact of Tourism on Rural Economies}

As previously stated, tourism represents a growing and significant source of revenue in Maine and other rural economies. In the United States, rural tourism is also experiencing growth as more people attempt to disconnect from urban life and focus on nature and relaxation (Nault, 2020). An interesting consequence of the recent COVID-19 pandemics is that people, especially younger people, are experiencing a "rebound" travel effect where they want to get outside and reconnect with nature (Palmer, 2021). As the "great resignation" takes hold, individuals seek more fulfilling ways to spend their time and energy (Hsu, 2021). Palmer notes, "Post-pandemic, 75 percent of Gen $\mathrm{Z}$ and Millennial travelers aspire to plan longer trips - and further afield, with 81 percent of respondents wanting to break away from standard holiday destinations " (2021). Rural communities with nature-based attractions should therefore benefit as they provide these natural, authentic experiences.

\section{Nature-Based Tourism and Sustainability}

Tourism is a broad umbrella, including a large swath of tourism-related activities such as travel, entertainment, food and beverages, travel and reservation products, and bus transportation. However, as our world has increasingly become technology-oriented, with computers and smart- phones as our constant companions, some people are finding the need to unplug and disconnect from them. A growing trend involves travelers seeking unique, authentic experiences with an awareness and appreciation for good environmental practices (CREST, 2019). People are beginning to recognize the benefits of a specific type of tourism labeled nature-based tourism. This type of tourism correlates with improvements in mental health, cognitive, physical, and immune response improvements, and stress reduction (Winter et al., 2020). Thus, it is not surprising that such tourism is a growing subset of the broader category of tourism. Tourism, in general, is a growth sector of the economy in the United States, increasing 62\% since 2000 (Bureau of Economic Analysis, 2021).

Given this, of particular interest to this research is the growth of tourism and employment from outdoor recreation and nature-based tourism. The sharp rise in adult participation in nature-based activities such as fishing (98\%) and recreational vehicle activities (48\%) is also relevant to this research (Bureau of Economic Analysis, 2021). Similarly, the impact of the pandemic on nature-based activities has been significant. According to the Outdoor Industry Association, over 8 million more Americans went hiking in 2020 compared to 2019. This trend is expected to continue, with forecasted growth of $14 \%$ over the next 20 years (Market Watch, 2021). All of this information taken together supports the need to research nature-based tourism to help small businesses in these rural areas.

Interestingly, this has been exacerbated by the COVID-19 pandemic as people have sought to find undisturbed uncrowded natural areas (Dingfelder, 2020). We studied three regions of Maine - Aroostook County, DownEast, and western Maine. They represent ideal targets for this type of tourism based on their rural locations, pristine landscapes, and outdoor activities. Yet, attracting people to these areas, no matter the beauty, can be very challenging. Taken together, this begs the question, how can we attract those tourists seeking a unique experience to the outskirts of rural counties? And, can the use of social media advertisements help draw out potential tourists?

\section{Challenge and Success Factors to Small Businesses in Rural Areas}

Therefore, we explore small businesses. According to the U.S Bureau of Labor Statistics, about 20\% of all small businesses fail within the first year, $50 \%$ by the fifth year, and $80 \%$ by the tenth year. These disturbing trends bring forth questions concerning how rural businesses can survive (Charles, 2017). Will digital technologies represent a way to overcome some of the challenges in reaching travelers seeking a unique travel experience and authentic scenery in sparsely populated areas? Is there a difference between small business owners who embrace the Internet and social media from those who do not? (Fachrunnisa et al., 2020; Reynolds et al., 2020). A fundamental question is whether U.S. small businesses also have an awareness of the need for social media outreach in the form of advertisement. 


\section{Use of Digital Technologies by Travelers}

The literature supports the suggestion that travelers use the Internet and social media to plan for travel destinations (Nizeyimana \& Kalulu, 2017). Similarly, because many travelers use smartphones while on the trip to search for activities, restaurants, and recommendations, they must consider providing appropriate content for these devices. Research by Longwoods International (2019) notes that about 55\% of travelers use social media to plan, assess, and review possible locations. About $68 \%$ of the travelers use Facebook and $82 \%$ who followed a social media influencer notice travelrelated content. Further research suggests $70 \%$ of travelers research travel on their smartphone, and $83 \%$ of U.S. adults now prefer to book their trip online (Condor, 2019). In terms of social media, a report from Statista showed that 36.5 percent of people use social media to plan travel, and 60 percent share photos on social media while traveling (Temblader, 2020).

Of specific interest to the present research, the Maine Office of Tourism (2019) reports that $65 \%$ of tourists use the Internet to plan trips and search for and reserve accommodations. Of these, $41 \%$ used TripAdvisor, 39\% Google Maps, and $33 \%$ online search engines for their research. Airbnb was also a well-used (30\%) search engine to find lodging. During their visit to Maine, $84 \%$ continued to use Internet searches, with $69 \%$ using their mobile devices to search. Most visitors (65\%) stayed in hotels, motels, or resorts during their visit, $18 \%$ in cabins/cottages, condos, $10 \%$ in Inns/ $\mathrm{B} \& \mathrm{Bs}$, and $3 \%$ in campgrounds. The average length of the stay was almost four nights. Most visitors came from the mid-Atlantic states (48\%), followed by New England (33\%) and Canada (17\%). Of these visitors, most visited the Maine beaches (23\%) as well as Acadia National park (Bar Harbor) (17\%). About $14 \%$ visited the western lakes and mountains area, and only 3\% saw the most rural part of Maine, Aroostook County. Of the limited visitors, $41 \%$ were most interested in touring/sightseeing, 36\% in outdoor activities (excluding water, mostly hiking), 33\% in food/culinary experiences, and $27 \%$ in water activities (mostly beach).

This data suggests that when planning a trip, tourists first research an area using the Internet. Given this, it appears keenly relevant for small businesses to harness digital strategies to reach and attract potential visitors. It also suggests that small businesses in rural areas might be best suited to provide visitors with local, authentic, friendly, high-quality experiences and guide visitors to help with outdoor activities and good food, history, and culture.

\section{Impact of the Internet and Social Media on Tourism in Rural Areas}

The prior section showed the decisive impact of the Internet and social media on traveler planning and usefulness during a vacation. The Theory of Planned Behavior (TPB) (Ajzen, 1985; Javed et al., 2020) helps explain the underlying motivation behind social media's impact on behavior. This theory suggests a linkage between behavioral intention and actual conduct. Using TPB, Javed et al. (2020) found that the Internet and social media were essential in helping tourists find and then plan vacations to more re- mote rural areas. A fascinating insight from their research was the importance of videos in influencing traveler behaviors to visit these areas. In addition, they discovered that finding and targeting "opinion leaders" in potential tourist segments was very effective in motivating travel behaviors. The use of videos was especially important with Millennials and perhaps with younger Gen $\mathrm{Z}$ travelers. In summary, their research showed that social media provided a significant way to reach tourists and tourism businesses and influence their travel behaviors.

Other researchers also find support for the relationship between proactive promotional activities, like Facebook advertisements, and increased tourist behaviors showing a positive relationship between sustained, aggressive promotional activities and tourist behavior (Cohen et al., 2014). They specifically noted that social media had become an increasingly important factor in influencing tourist behaviors and decisions for trip planning and selecting activities, destinations, lodging, dining, and shopping during the trip. A study by Sarbu et al. (2018) found that the most influential tourism advertising uses a combination of Facebook and Instagram, with a maximum penetration rate when running ads on those two platforms in parallel.

\section{Social Media Engagement and Tourist Behaviors}

It appears logical that consumers are interested in the tourism of rural areas. Still, the critical component of the discussion is how to encourage customers to move from scrolling to engaging with a particular website or location. To this end, we turn to the work of Vale \& Fernandes (2018). They define the construct of Consumer Engagement Behavior (CEB) as the behavioral indicators of attitudes and motivations towards a brand, product, or service offerings. They suggest that CEB related activities might be defined by a typology proposed by Muntinga et al. (2011) to help provide meaning to how consumers interact with Online resources. The model labeled the Consumers Online BrandRelated Activities (COBRA) (Muntinga et al., 2011) provides a model of how people engage in social media and how that might drive their behavior, precisely consumer motivation for engaging with particular brand-related content. Of specific interest to the present research is the path of gradual involvement with brand-related content. The model suggests that the minimum level of engagement is consuming defined as viewing content through passive engagement. The second level is contributing, engaging with the online resource by commenting on the product, which is reflected on their own social media page. The third level is creating. Creating occurs when people comment and share the content. Researchers have found that the relevant motivation to consume social media rests on the desire for entertainment, integration and social interaction, personal insights, and information (Papacharissi, 2007).

\section{Advertising and Social Media}

Advertising was first introduced in 1923 by Claude Hopkins in a book called Scientific Advertising. However, numerous strides in advertising have occurred over time and lead to the present discussion about the interaction between social media and advertising. Researchers note that 
social media advertising is different from traditional advertisements, and consumers can exert both positive and negative influence over the product (Muntinga et al., 2017). Others have found that consumer involvement in the brand (reposting, sharing, liking, etc.) can positively and substantially affect the brand (Manchanda et al., 2015). And such advertising methods are far more effective than the traditional push-based marketing models (Trusov et al., 2009). Given this, it is relevant to consider the impact of an advertisement on one's willingness to engage in the content. Therefore, our hypotheses will explore social media advertising relative to the COBRA model and potential increased visits to these rural areas.

\section{Research Model}

Examining the COBRA typology in more detail will help define our hypotheses as the levels of engagement put forth by the COBRA framework are a standard used to measure social media effectiveness (Buzeta et al., 2020). The three behavioral levels are Consumption, Contribution, and Creation (Muntinga et al., 2011). The first, called Consumption, is defined as passive, low-level activities such as receiving the post, looking at the posts, reading posts, perhaps clicking on the content, but not actively engaging or participating in the social media post. Such behaviors are broadly passive, representing the minimum level of interaction with the post. Given this passive activity level, the COBRA model refers to Consumption as the lowest level of engagement and the most frequent consumer activity. Consumption is further specified as motivation for entertainment and tends to be an antecedent to other forms of Consumption. Thus, it is relevant to examine if a paid advertisement might lead to additional Consumption. In the present model, we separated Consumption into two categories: pre-consumption and Consumption. Said more formally, we hypothesize:

H1. Using a paid social media advertisement will positively and significantly increase the Pre-Consumption (receiving and reading the post) of the social media post.

H1a. Using a paid social media advertisement will positively and significantly increase Consumption (clicking on the content).

The second level in the COBRA model refers to, Contribution which is considered the medium level of consumer involvement. It involves the consumer interacting with the post via likes, loves, and wows over a post. It is signified by both user-to-content and user-to-user interaction. Contribution appears to increase a consumer's level of interest and loyalty. Given this, it is captured in the present study as the total number of likes, loves, and wows. Said more formally, we hypothesize:

H2. Using a paid social media advertisement will positively and significantly increase Contribution (likes, loves, wow).

The highest level of engagement, Creation, is when consumers actively contribute to the post with comments, shares, actively engaging with others, uploading photos, or using hashtags. This activity further stimulates activity and engagement by peers. Therefore, the more active the engagement (CEB) in a social media post, the more interested and engaged the consumer will be in further actions and be- haviors such as purchase or travel activities. Given this, we formally hypothesize:

H3. The use of a paid social media advertisement will positively and significantly increase Creation (comments, shares).

We use the consumer engagement model specified by Vale and Fernandes (2018) and Ferreira et al. (2020) to measure engagement from a holistic standpoint. Gudigantala et al. (2016) explored the relationship between purchasing intent and conversion rates to actual purchases. While this study examined these behaviors for e-commerce stores, their findings can translate to destination advertising and travel conversions. They found that trust and satisfaction with the website had a significant positive correlation with the conversion rates. Thus, we argue that social media ads will drive potential tourists to a business's website. These ads can impact the conversion rate by motivating people to visit these areas and spend money. Visiting the website and interacting with the website is a trusting action and signals trust in and satisfaction with the website, its content, and credibility (Flavián et al., 2006). Thus, the total interactions with the post can be a proxy for the potential of visitation or purchase (Kim et al., 2017). To this end, we aggregate the previously defined variables to create an engagement variable. Using this, we formally hypothesize:

H4. Using social media paid advertisement will positively and significantly increase the Engagement rate (overall engagement with the post).

\section{Data Collection}

We collected data from a student-centered research project called "Undiscovered Maine," which is part of the University of Maine Business School. This project has been working to promote small businesses in rural areas of Maine over the past eight years. The project uses Facebook as a vehicle to promote small businesses, activities, and places in these rural businesses. Over a one-year period, approximately 120 posts were created. We accessed the data for each of these posts using Facebook Insights, which provided data on reach, likes, loves, comments, shares, and post clicks.

The present study utilized data collected between Spring 2020 to Spring 2021 from the Undiscovered Maine project's Facebook page. The study uses this data with a deductive research approach which quantitatively analyzes a large set of independent data. Specifically, over 12 months, we obtained over 100,000 separate pieces of data gathered to represent 126 different event posts over one year. In this study, 20 posts used paid advertisements on Facebook, and the remaining 105 did not use paid advertisements. We then used statistics to examine differences between engagement between paid ads and no ads. For more information on how to generate such an advertisement, please see Appendix 1. The sample description is in Table 1.

\section{Analytics}

The social media platform Facebook provides analytics to offer insights to monitor the response to Facebook posts 
Table 1. Descriptive Statistics

\begin{tabular}{|c|c|c|c|c|c|c|c|}
\hline & & $\mathrm{N}$ & Mean & Std. Deviation & Std. Error & Min & Max \\
\hline \multirow{3}{*}{$\begin{array}{l}\text { Pre-Consumption } \\
\text { (Reach) }\end{array}$} & No Ad & 101 & 192.10 & 227.468 & 22.634 & 51 & 1442 \\
\hline & Paid Ad & 20 & 3714.55 & 2274.047 & 508.492 & 392 & 7862 \\
\hline & Total & 121 & 774.32 & 1608.739 & 146.249 & 51 & 7862 \\
\hline \multirow{3}{*}{$\begin{array}{l}\text { Consumption } \\
\text { (Post Clicks) }\end{array}$} & No Ad & 101 & 14.09 & 35.439 & 3.526 & 0 & 241 \\
\hline & Paid Ad & 20 & 370.00 & 292.507 & 65.406 & 17 & 930 \\
\hline & Total & 121 & 72.92 & 179.488 & 16.317 & 0 & 930 \\
\hline \multirow{3}{*}{$\begin{array}{c}\text { Contribution } \\
\text { (Likes, Loves, \& Wows) }\end{array}$} & No Ad & 101 & 16.13 & 35.174 & 3.500 & 0 & 197 \\
\hline & Paid Ad & 20 & 41.10 & 32.490 & 7.265 & 5 & 160 \\
\hline & Total & 121 & 20.26 & 35.846 & 3.259 & 0 & 197 \\
\hline \multirow{3}{*}{$\begin{array}{c}\text { Creation } \\
\text { (Comments \& Shares) }\end{array}$} & No Ad & 101 & 3.74 & 9.392 & 0.935 & 0 & 57 \\
\hline & Paid Ad & 20 & 14.85 & 13.666 & 3.056 & 1 & 53 \\
\hline & Total & 121 & 5.58 & 10.966 & 0.997 & 0 & 57 \\
\hline \multirow[t]{3}{*}{ Engagement } & No Ad & 96 & 0.86 & 0.651 & 0.066 & 0 & 4 \\
\hline & Paid Ad & 20 & 1.91 & 0.279 & 0.062 & 1 & 2 \\
\hline & Total & 116 & 1.04 & 0.723 & 0.067 & 0 & 4 \\
\hline
\end{tabular}

and engagement with the content, sharing activity, and demographics and geographic information for content supported by Facebook ads. We created a data set to examine the relationship between the impact of the advertisements and consumer interaction with the content. The spreadsheet captured the following Facebook data: date and description of the post, paid ad (yes or no), post reach (the number of people who saw your posts in their timeline; both organic and paid ads; reach measures unique views), post clicks (the total number of clicks on a post, not including comments, likes, and shares), page views (the number of times people have viewed a Page's profile), comments, shares, and likes/loves/wows, and overall post engagement (Includes all actions that people take involving your ads while they're running. Post engagements can include reacting to, commenting on, sharing the ad, claiming an offer, viewing a photo or video, or clicking on a link).

In the one year of data collection, the site collected 109,107 separate user interactions, broken into the categories: Pre-Consumption, Consumption, Creation, Contribution, and Engagement, each described in Table 1: Descriptives.

\section{Measures}

This research is an exploratory study. We seek to understand better how small businesses in rural, underserved areas can reach potential tourists via cost-effective strategies. The U.S. Census describes rural regions of the United States as "sparsely populated, have low housing density, and are far from urban centers” (Census.gov, 2017).

Social media outreach: The present research utilizes social media to assess and investigate the hypothesis put forth in this research. Specifically, most of these data come from Facebook, as this website enables users to indicate if they like the post and interact with the material in real-time. The analytics side of Facebook then allowed us to measure and monitor these interactions over time. Of specific interest to the present research is the potential ' 'tourist's engagement with the following site features:

- Advertisement (Ad): We boosted specific Facebook posts with paid advertisements. The placement of an advertisement (Ad) is the independent variable in this study. It is represented as a dummy variable where one equates to a paid advertisement for an event, and 0 corresponds to an event without a paid advertisement. Ads were placed randomly across the one-year data collection timeframe

- Pre-Consumption: The number of people who saw a post in their timeline using both organic and paid ads; Pre-consumption is measured by Reach, which captures unique views.

- Consumption: Measured by post clicks which indicate that a person clicked somewhere within the post. This could be on a link, a picture, etc.

- Contribution: The number of new likes, loves, and wows for the content. This represents (broadly) one's propensity to enjoy a place promoted in the advertisement and asserts a willingness to visit this location.

- Creation: This is the highest level of engagement with the post when people take the time to comment and/or share the post.

- Engagement: This is a summation of Consumption, Contribution, and Creation measured by adding together the number of post-clicks, likes, loves, wows, shares, and comments. CEB shows the overall level of involvement by people who see the post.

\section{Analysis}

Before proceeding with this analysis, the data were examined for normalcy, unexpected correlations, and the presence of outliers. As can be seen in Table 1: Descriptives, the data is positively skewed in all cases suggesting that 
a few significant data points pull out the mean, shifting it in all cases to the right of the median. However, none of the data represents significant outliers, and there is a large enough sample to suggest the data could support the usage of normal statistics. Also, because the dependent variables are related by their very nature, the only independent variable in this analysis is the existence or absence of an advertisement, quantified as a dummy variable. The dummy variable is a 1 when there is a paid advertisement and a 0 when there is no advertisement. To this end, we chose to regress the dummy variable on each of the dependent variables put forth in the hypotheses.

\section{Results}

Hypothesis 1 suggests that placing a paid advertisement will increase the Pre-Consumption (Reach) of the social media post. This hypothesis seeks to quantify the idea of Consumption of social media. The relationship was explored through the use of an OLS regression model. The placement of the ad is the independent variable utilized to predict the reach of the site. Our results indicate that placing an ad creates a statistically significant impact on the reach of the site. Utilizing an OLS regression model, we find that for each paid advertisement, pre-consumption increases by about 3,522 units, which is statistically significant $(\mathrm{t}=$ $15.438, \mathrm{p}<0.01$ ), and the placement of an advertisement seems to explain more than $66 \%$ of the variation in PreConsumption, providing support for Hypothesis 1.

Hypothesis 1a is designed to examine the relationship between advertisement Consumption (Post Clicks). This hypothesis seeks to add additional evidence to the idea of Consumption of social media. With Post Clicks, the viewer has gone beyond being reached and engaged with the medium in a meaningful manner. As noted in the literature review, exploring and finding out more about a locale is an antecedent of actual visits, so this measure is important. To that end, utilizing an OLS regression model, we find that consumption increases by about 356 views for each paid advertisement. Such a result is statistically significant, suggesting these results are very unlikely to have been obtained by chance $(t=11.987, \mathrm{p}<0.01)$. Further, we find this variable explains more than $54 \%$ of the variation in Consumption. Thus, we find support for Hypotheses 1a.

Hypothesis 2 examines the relationship between posting an advertisement and people Contributing to the content through the process of liking, loving, or wowing the post with their friends. This sort of action on the part of the viewer is a movement towards Contribution. Like landing page views, the theory indicates that people who like a post are an indication of interest and a precursor that they will visit the site. Thus, we utilize an OLS regression model to examine the impact of the advertisement on likes, loves, and wows. When an advertisement is not present, the analysis shows that we expect to see approximately 16 like, loves, and wows per post. However, when an advertisement is present, this increases by about $156 \%$. Such a finding is statistically significant, suggesting that the likelihood of obtaining these results through a random event is less than $1 \%(t=2.935, p<0.01)$. Also of interest is that the advertisement can explain almost $7 \%$ of the variation in likes, loves, and wows. Taken together, when an ad is present, we can expect approximately 41.09 likes or loves of the location.

Hypothesis 3 attempts to examine the impact of placing an advertisement on a viewer Creating new content as a result of the post. In this case, people are putting their own words or vote of confidence behind the post. To classify as creating, the social media user needs to comment or share the content. Such an action on the viewer's part suggests even more significant movement towards visiting the rural location, an even stronger indicator that they will visit the site. To that end, we utilize an OLS regression model to examine the impact of the advertisement on Creation. When an advertisement is not present, the analysis shows that we expect to see approximately four comments and shares. However, when an advertisement is present, this increases by about $175 \%$. Such a finding is also statistically significant. $(\mathrm{t}=4.451, \mathrm{p}<0.01)$. Also of interest is that the advertisement can explain more than $14 \%$ of the variation in comments and shares. Taken together, when an advertisement is present, we can expect approximately 15 comments and shares.

Hypothesis 4 attempts to capture the broad engagement rate of the users. As opposed to the individual measures, $\mathrm{H} 4$ attempts to capture a combination of engagement activities that is not discoverable when analyzing each type of engagement individually. While we cannot be certain that this will lead to actual visitors to the undiscovered rural location, it is a clear indicator of interest. The Engagement measure is computed through the summation of Pre-consumption, Consumption, Contribution, and Creation. In this formation, researchers can assess the actionable steps taken from a post or the overall involvement by people who see the post. It is a reliable measure of one's actual intent to visit the physical location (Schivinski et al., 2016). The measure ranges from 51 to 8,451 , with a skewness of 2.7 , suggesting that extreme values are concentrated in the distribution's right tail, pulling the mean relative to the median and bulk of the data. However, given the large data set, we proceed with the actual data, which supports hypothesis 4. On average, the rural locations queried in this research are likely to see an average of 226 units of engagement (the sum of Reach, Consumption, Creation, and Contribution). However, when a paid advertisement is utilized, the same rural locations are likely to see a jump to 3,914 units of engagement. Such an increase represents a significant effect, $(t=15.463, p<0.01)$. This analysis also suggests that about $66.5 \%$ of the outcome can be accounted for with an advertisement. Table 2 presents the results of the analysis. 
Table 2. Regression Results

\begin{tabular}{|c|c|c|c|c|c|c|c|c|c|}
\hline & & \multicolumn{2}{|c|}{ Unstandardized Coefficients } & \multicolumn{3}{|c|}{ Standardized Coefficients } & \multicolumn{3}{|c|}{ Model Significance } \\
\hline & & B & Std. Error & B & $\mathrm{t}$ & Sig. & $\mathbf{F}$ & Sig. & R Square \\
\hline \multirow{2}{*}{ Hypothesis 1: Paid Ad on Pre-Consumption } & (Constant) & 192.099 & 92.765 & & 2.071 & 0.041 & 238.321 & $0.000^{* *}$ & $66.70 \%$ \\
\hline & Paid Ad Dummy & 3522.451 & 228.173 & 0.817 & 15.438 & 0.000 & & & \\
\hline \multirow{2}{*}{ Hypothesis 1a: Paid Ad on Consumption } & (Constant) & 14.089 & 12.071 & & 1.167 & 0.245 & 143.698 & $0.000^{* *}$ & $54.70 \%$ \\
\hline & Paid Ad Dummy & 355.911 & 29.690 & 0.740 & 11.987 & 0.000 & & & \\
\hline \multirow{2}{*}{ Hypothesis 2: Paid Ad on Contribution } & (Constant) & 16.129 & 3.459 & & 4.663 & 0.000 & 8.616 & $0.004^{* *}$ & $6.80 \%$ \\
\hline & Paid Ad Dummy & 24.971 & 8.507 & 0.260 & 2.935 & 0.004 & & & \\
\hline \multirow{2}{*}{ Hypothesis 3: Paid Ad on Creation } & (Constant) & 3.743 & 1.014 & & 3.689 & 0.000 & 19.814 & $0.000^{* *}$ & $14.30 \%$ \\
\hline & Paid Ad Dummy & 11.107 & 2.495 & 0.378 & 4.451 & 0.000 & & & \\
\hline \multirow[b]{2}{*}{ Hypothesis 4: Paid Ad on Engagement } & (Constant) & 226.059 & 102.059 & & 21.284 & 0.000 & 172.704 & $0.000^{* *}$ & $59.2 \%$ \\
\hline & Paid Ad Dummy & 3914.441 & 253.144 & 0.817 & 15.563 & 0.000 & & & \\
\hline
\end{tabular}

** Statistically Significant to .01 
Finally, in the interest of supporting small businesses in Maine, it seems important to translate one of the COBRA model variables to something more tangible and easier to understand. To that end, we provide an example of the power of advertisement via Facebook and the interaction with Contribution. When a small business does not place an advertisement on Facebook, the business generally accumulates approximately 16 Contributions (likes, loves, shares, and wows). However, when the same small rural business places an ad on Facebook, they are likely to gain an average increase of approximately 25 likes, loves, wows, expanding the Contribution from 16 to 41 . This can be seen in the equation below, and provides evidence of statistical significance and provides face validity. Such results are evident.

$$
\begin{gathered}
\widehat{Y}=\beta_{0}+\beta_{1} X_{1}+\varepsilon \\
41.100=16.129+24.971
\end{gathered}
$$

\section{Discussion}

The purpose of this paper was to explore feasible methods that small businesses in rural, under-served regions of Maine could use to increase tourism, and thus economic development. We demonstrated the growth of nature-based tourism as a good fit for these rural areas, including Aroostook County, DownEast, and Western Maine. They all have phenomenal natural environments, a plethora of outdoor, nature-based activities, and the authentic rural experience that many tourists in these segments are seeking.

Customer engagement behavior (CEB) appears to be influenced by digital advertising and social media. The "COBRA" model shows the relationship between different social media engagement responses and behavioral engagement. To reiterate, these researchers suggest that "Consumption," the most frequent activity, is viewed as more passive, lowlevel activities such as reading posts, perhaps clicking on the content, but not actively engaging or participating in the social media post. The second level, "Contribution," usually involves posts such as likes, comments, or shares. This has been shown to increase their level of interest and loyalty. The last and highest level of engagement, "Creation, "is when consumers actively contribute to the post, posting reviews, comments, actively engaging with others, uploading photos, or using hashtags (Muntinga et al., 2011).

Our data show a significant increase in all levels of engagement with paid ads on Facebook. Based on our analysis, we validated our hypotheses, demonstrating the statistical significance and the impact of using paid Facebook ads to increase reach and subsequent engagement. More importantly, a significant increase in engagement was shown by likes, loves, wows, comments, shares, and post clicks on the web page under the ad condition. What we found interesting was the level of engagement showing the paid ad's impact on driving people to the specific page on the website from the ad. We can infer that if people take the time to visit the web page, these behaviors can potentially lead to actions in visiting the destination as consistent with the “Tourist advertising response" models (Choe et al., 2017). These models indicate that tourist decisions while on vacation are influenced by destination tourism advertising, showing higher visitations and more money spent than people who did not see this advertising. We also found that more personal ads created a greater overall engagement across all criteria, including reach, post clicks, likes/loves, comments and shares. For example, an ad for a local farm created more engagement than an ad for a destination because people either knew or could relate more to the farm in a more personal way.

Research indicates that this type of social media engagement leads to tangible benefits such as purchases and "unacknowledged positive outcomes" in the form of intangible benefits (Pelletier \& Horky, 2015). Drawing on this literature, we can draw some conclusions about the value of tangible and intangible benefits of engagement.

One measure of tangible value is through the monetization of visitor engagement, such as Facebook likes. Conversion rates from clicking a Facebook Like to making an actional purchase have been reported as likely (21\%) to very likely (3\%), indicating that a sizable number of Likes convert to actual purchase (Bushelow, 2012). There is some ambiguity regarding the value of a like with P.C. World reporting the value of a Like could range from nothing to as high as $\$ 214.81$ for a non-profit organization (Chacos, 2012). While this is a rather large range given that the costs of our ads in the study were around $\$ 30$, even at the lower end of the value range (of only a few dollars) would easily justify the use of an ad. Research seems to agree that the value comes from making consumers aware of a brand and gathering information from consumers' engagement in social media (Bendle \& Bagga, 2016; John et al., 2017; Mochon et al., 2017).

Customer engagement creates influence beyond monetization. For example, simple exposure (i.e., reach) builds awareness of rural business and recreation opportunities, forming a foundation for future exploration and engagement (Davenport \& Beck, 2001). Beyond awareness, Gudigantala et al. (2016) found that trust and satisfaction with the website significantly correlated with conversion rates. Thus, after driving potential tourists to our Undiscovered Maine website via social media advertising, literature shows that the conversion rate motivates people to visit these areas and spend money. This could also eventually build trust in and satisfaction with the website, its content, and credibility.

From this study, we contribute to both the literature and practice. This study adds to the understudied area of business development in rural communities by exploring the connection between social media advertising and resultant actions. This field study gathered user reactions instead of less realistic settings in a simulated environment or with student populations. Our study has practical implications as well. Business owners and organizations in rural areas have extremely limited resources and do not always have the luxury of experimenting and trying different strategies. Prior research has found that digitization improves operational efficiency and adds to market flexibility (Rosin et al., 2020). We extend these findings with our study results, reassuring rural businesses and organizations that using social media ads is worth the time and effort.

As exploratory in nature, our research does have a few limitations. First, the study was done in one geographic location - remote and rural Maine. While we can assume that 
many aspects of the study will readily translate to other remote rural areas, additional studies may be warranted to confirm the generalizability. Additionally, the size of the study precluded us from capturing subsequent intangible and tangible benefits, and the nature and timing of the advertisements may have influenced our results. Other research could be conducted to test our assumptions based on current literature. Further, future studies might also consider the role of social commerce as it relates to rural areas. The nature of the rural business's product or target market may influence the impact of advertising, and so further studies should take place to clarify these nuances. While our study may act as a precursor to such studies, more research into the role of social commerce within rural areas would be beneficial.

\section{Conclusion}

Our data supports all our hypotheses, suggesting a statistically significant relationship between the placement of a social media advertisement and potential visitor interest and engagement with the content. This is supported by all the major metrics involved with visitor engagement, preconsumption, Consumption, Creation, and Contribution. While prior research in tourism suggests the relationship between consumer behavior intentions and actions, the present research is the first of its kind to test this relationship in small rural businesses. 


\section{REFERENCES}

Ajzen, I. (1985). From intentions to actions: A theory of planned behavior. In J. Kuhl \& J. Beckmann (Eds.), Action control: From cognition to behavior (pp. 11-39). Springer. https://doi.org/10.1007/978-3-642-6974 6-3_2

Bendle, N. T., \& Bagga, C. K. (2016). Should you use the value of a "like" as a metric? MIT Sloan Management Review. https://sloanreview.mit.edu/article/should-yo u-use-the-value-of-a-like-as-a-metric/

Bureau of Economic Analysis. (2021). Tourism sales and employment by tourism commodity: 2000 To 2019 [selected years] proquest statistical abstract of the u.s. 2021 online edition. https://statabs-proquest-com.wvo-ursus-proxy02.ursus.maine.edu/sa/docview.html?ta ble-no $=1283 \&$ acc - no $=$ C $7095-1.26 \&$ year $=2021 \& z=F E$ D618C7E56234041E05E5BF5CB6705BC97F31CF\&r $\mathrm{c}=1 \&$ seq $=0$ \&accountid $=14583 \& \mathrm{y}=$ current $\& \mathrm{q}=$ tourism

Bushelow, E. E. (2012). Facebook pages and benefits to brands. Elon Journal of Undergraduate Research in Communications, 3(2), 1-4.

Buzeta, C., De Pelsmacker, P., \& Dens, N. (2020). Motivations to use different social media types and their impact on consumers' online brand-related activities (COBRAs). Journal of Interactive Marketing, 52, 79-98. https://doi.org/10.1016/j.intmar.2020.04.0 $\underline{04}$

Census.gov. (2017). What is rural America? https://ww w.census.gov/library/stories/2017/08/rural-america.ht $\underline{\mathrm{ml}}$

Chacos, B. (2012). What's a Facebook "like" worth? PCWorld. https://www.pcworld.com/article/2011309/ whats-a-facebook-like-worth.html

Charles, J. (2017). Top 10 challenges small business owners are facing today. Small Business Trends. http s://smallbiztrends.com/2017/10/biggest-challenges-f or-small-business-owners.html

Choe, Y., Stienmetz, J. L., \& Fesenmaier, D. R. (2017). Measuring destination marketing: Comparing four models of advertising conversion. Journal of Travel Research, 56(2), 143-157. https://doi.org/10.1177/004 $\underline{7287516639161}$

Cohen, S. A., Prayag, G., \& Moital, M. (2014). Consumer behaviour in tourism: Concepts, influences and opportunities. Current Issues in Tourism, 17(10), 872-909. https://doi.org/10.1080/13683500.2013.850 $\underline{064}$

Condor. (2019). Over 70+ online travel booking statistics (2020-2021). Condor Ferries. https://www.condorferrie s.co.uk/online-travel-booking-statistics

CREST. (2019). The case for responsible travel: Trends \& statistics 2019. https://www.gstcouncil.org/case-respo nsible-travel-trends-statistics-2019/

Dakota News. (2021). South Dakota tourism performed better than other states in 2020.

Https://Www.Dakotanewsnow.Com. https://www.dak otanewsnow.com/2021/01/21/gov-noem-gives-updat e-on-state-tourism-economic-impact/
Davenport, T., \& Beck, J. (2001). The attention economy: Understanding the new currency of business. Harvard Business School Press.

Dingfelder, S. (2020). Nurtured by Nature- How the pandemic has intensified our connection to the outdoors. Washington Post. https://www.washingtonp ost.com/magazine/2020/12/28/isolation-pandemic-ca used-her-form-new-intense-relationship-nature-shewas-hardly-alone/

Fachrunnisa, O., Adhiatma, A., Majid, M. N. A., \& Lukman, N. (2020). Towards "SMEs" digital transformation: The role of agile leadership and strategic flexibility. Journal of Small Business Strategy, 30(3), 65-85.

Ferreira, M., Zambaldi, F., \& Guerra, D. de S. (2020). Consumer engagement in social media: Scale comparison analysis. Journal of Product \& Brand Management, 29(4), 491-503. https://doi.org/10.1108/ jpbm-10-2018-2095

Flavián, C., Guinalíu, M., \& Gurrea, R. (2006). The role played by perceived usability, satisfaction and consumer trust on website loyalty. Information \& Management, 43(1), 1-14. https://doi.org/10.1016/j.i $\underline{\mathrm{m} .2005 .01 .002}$

Gudigantala, N., Bicen, P., \& Eom, M. (2016). An examination of antecedents of conversion rates of ecommerce retailers. Management Research Review, 39(1), 82-114. https://doi.org/10.1108/mrr-05-2014-0 112

Hsu, A. (2021). As the pandemic recedes, millions of workers are saying “I quit.” NPR. https://www.npr.org/ 2021/06/24/1007914455/as-the-pandemic-recedes-mi llions-of-workers-are-saying-i-quit

Javed, M., Tučková, Z., \& Jibril, A. B. (2020). The role of social media on tourists' behavior: An empirical analysis of millennials from the Czech Republic. Sustainability, 12(18), 7735. https://doi.org/10.3390/s $\underline{\mathrm{u} 12187735}$

John, L. K., Mochon, D., Emrich, O., \& Schwartz, J. (2017). What's the value of a like? Harvard Business Review. https://hbr.org/2017/03/whats-the-value-ofa-like

Kennedy, K. (2021). Tourism in the US: NNOO2. IBISWorld.

Kim, S., Kim, J., \& Park, S. (2017). The effects of perceived value, website trust and hotel trust on online hotel booking intention. Sustainability, 9(12), 2262. https://doi.org/10.3390/su9122262

Lane Report. (2019). Report: Rural small business owners face unique challenges. Lane Report | Kentucky Business \& Economic News. https://www.lanereport.co m/110475/2019/02/report-rural-small-business-wwn ers-face-unique-challenges/

Longwoods International. (2019). Colorado come to live: Travel year 2019 (p. 180). https://www.industry.colora do.com/sites/default/files/Colorado\%202019\%20fina 1\%20report_online.pdf 
Maine Office of Tourism. (2019). 2019 Maine office of tourism highlights. https://motpartners.com/wp-conte nt/uploads/2020/06/2019_Maine_Tourism_Highlight s.pdf

Manchanda, P., Packard, G., \& Pattabhiramaiah, A. (2015). Social dollars: The economic impact of customer participation in a firm-sponsored online customer community. Marketing Science, 34(3), 367-387. https://doi.org/10.1287/mksc.2014.0890

Market Watch. (2021). Global ecotourism market size study, by type (alternative tourism, responsible tourism, sustainable tourism, community tourism), by Application (below 20 years, 20-50 years, above 50 years) and regional forecasts 2019-2026. https://ww w.marketwatch.com/press-release/global-ecotouris m-market-size-study-by-type-alternative-tourism-re sponsible-tourism-sustainable-tourism-community-t ourism-by-application-below-20-years-20-50-years-a bove-50-years-and-regional-forecasts-2019-2026-202 1-02-25?tesla $=\mathrm{y}$

Mochon, D., Johnson, K., Schwartz, J., \& Ariely, D. (2017). What are likes worth? A Facebook page field experiment. Journal of Marketing Research, 54(2), 306-317. https://doi.org/10.1509/jmr.15.0409

Muntinga, D. G., Moorman, M., \& Smit, E. G. (2011). Introducing COBRAs: Exploring motivations for brand-related social media use. International Journal of Advertising, 30(1), 13-46. https://doi.org/10.2501/ij a-30-1-013-046

Muntinga, D. G., Moorman, M., Verlegh, P. W. J., \& Smit, E. G. (2017). Who creates brand-related content, and why? The interplay of consumer characteristics and motivations. In Digital advertising (pp. 259-284). Routledge. https://doi.org/10.4324/9781315623252-1 $\underline{5}$

Nault, A. (2020). Tourism trends 2021 - Urban, cultural, rural. https://www.tourism-review.com/next-years-to urism-trends-news 11768

NCSL. (2020). Challenges facing rural communities. http s://www.ncsl.org/research/agriculture-and-rural-deve lopment/challenges-facing-rural-communities.aspx

Nizeyimana, J. P., \& Kalulu, R. (2017). The effective use of social media as a competitive advantage in tourism industry "A case study of Rwanda rural tourism destination areas”, 22. ATLAS Africa Conference.

Palmer, S. (2021). Glampervans and the death of minibreaks: All the 2021 travel trends. Euronews. https://w ww.euronews.com/travel/2021/05/12/here-s-what-ex perts-are-forecasting-for-the-travel-industry-in-2021

Papacharissi, Z. (2007). Audience as media producers: Content analysis of 260 blogs. In M. Tremayne (Ed.), Blogging, citizenship and the future of media (pp. 21-38). Routledge.

Pelletier, M. J., \& Horky, A. B. (2015). Exploring the Facebook like: A product and service perspective. Journal of Research in Interactive Marketing, 9(4), 337-354. https://doi.org/10.1108/jrim-09-2014-0059
Reynolds, S., Cotrino, F., Ifedi, C., \& Donthu, N. (2020). An exploratory study of executive factors that lead to technology adoption in small businesses. Journal of Small Business Strategy, 30(2), 1-16.

Robertson, A. (2021). How COVID-19 changed Idaho tourism and what's next for Boise, McCall, Sun Valley \& beyond. BoiseDev. https://boisedev.com/news/2021/0 5/19/idaho-tourism-2021/

Rosin, A. F., Proksch, D., Stubner, S., \& Pinkwart, A. (2020). Digital new ventures: Assessing the benefits of digitalization in entrepreneurship. Journal of Small Business Strategy, 30(2), 59-71.

Sarbu, R., Alecu, F., \& Dina, R. (2018). Social media advertising trends in tourism. Amfiteatru Economic, 20(S12), 1016. https://doi.org/10.24818/ea/2018/s12/1 $\underline{016}$

SBA Office of Advocacy. (2019). Maine Small Business Profile. https://cdn.advocacy.sba.gov/wp-content/upl oads/2019/04/23142650/2019-Small-Business-Profile s-ME.pdf

Schivinski, B., Christodoulides, G., \& Dabrowski, D. (2016). Measuring “consumers” engagement with brand-related social-media content: Development and validation of a scale that identifies levels of social-media engagement with brands. Journal of Advertising Research, 56(1), 64-80. https://doi.org/1 0.2501/jar-2016-004

Temblader, A. (2020). How the Decade's Rise of Social Media Changed Travel. Travel Pulse. https://www.trav elpulse.com/news/features/how-the-decades-rise-ofsocial-media-changed-travel.html

Trusov, M., Bucklin, R. E., \& Pauwels, K. (2009). Effects of word-of-mouth versus traditional marketing: Findings from an internet social networking site. Journal of Marketing, 73(5), 90-102. https://doi.org/1 $\underline{0.1509 / j m k g .73 .5 .90}$

U.S. Census Bureau. (2016). New census data show differences between urban and rural populations, American community survey, 2011-15. The United States Census Bureau. https://www.census.gov/newsr oom/press-releases/2016/cb16-210.html

U.S. Department of the Interior. (2020). National park visitor spending generates economic impact of more than $\$ 41$ billion. https://www.doi.gov/pressreleases/na tional-park-visitor-spending-generates-economic-im pact-more-41-billion

Vale, L., \& Fernandes, T. (2018). Social media and sports: Driving fan engagement with football clubs on Facebook. Journal of Strategic Marketing, 26(1), 37-55. https://doi.org/10.1080/0965254x.2017.1359655

Winter, P. L., Selin, S., Cerveny, L., \& Bricker, K. (2020). Outdoor recreation, nature-based tourism, and sustainability. Sustainability, 12(1), 81. https://doi.or g/10.3390/su12010081 


\section{Appendix 1}

Facebook ads were placed to showcase different aspects of the Undiscovered Maine project. These included specific activities, itineraries, small business success stories, towns and unique Maine recipes. To place a Facebook ad, the process includes:

1. Create a Facebook post for the activity of interest

2. Click on "Boost Post" within the post or go into the "Manage Page" on your Facebook page and then click in the "Ad Center" link in the left navigation bar and click on the blue "Create Ad" button on the right side.

3. To set the parameters for the ad:

a. Goal: click the down arrow for options. We wanted to bring visitors to our website, we clicked on "Get more website visitors" for our goal. Scroll down to the "Audience" section and click on the edit icon, which looks like a pencil.

b. Gender: specify your preferences

c. Location: Type in the geographic areas you would like to reach

d. Detailed targeting: type in keywords that would be appropriate. For example, if we were promoting a hiking itinerary, we would type in keywords like hiking, nature tourism, etc.

e. Duration: Enter how long you would like the ad to run. We used 6 days for our ads.

f. Total budget: enter the total amount that you would like to spend. We spent a total of $\$ 30$ for each ad. Therefore, with the ad running for 6 days, it cost us $\$ 5.00$ per day.

g. Enter your payment information.

4. When you are satisfied with the ad parameters, click on the blue "Boost Post Now" button on the bottom right.

5. The Facebook team will review the ad and send an email when it is approved and running.

6. To see ad results, go into your Facebook page and click on "Insights". This section provides the details that were described in the prior section. 